\title{
Text and Image in the Digital Age - The Digital Revolution
}

\author{
Ion Gherman
}

\author{
West University of Timişoara, Faculty of Arts and Design
}

Received 16 June 2018 • Revised 20 July 2018 • Accepted 22 July 2018

\begin{abstract}
The paper discusses the place and role played by the pictures and text in the digital era. The digital art has become an essential component of contemporary art and new tools currently available to artists are revolutionizing the way they think and create, and so, artistic projects that could not have been accomplished with traditional methods, are now possible through computer interfaces. The computers have facilitated the traditional processes, and also offered a whole new vision on the sketches and the idea forming process, allowing the artists to create many virtual versions of an artwork - a concept. In order to analyze the history of digital art, it is necessary to study the history of several disciplines: computer history as visual medium, the history of graphic design and computer history integrated in the visual arts. Often these disciplines coincide during certain periods, making the study even more difficult to conduct. This chapter presents a brief history of computer generated art, of deconstructive typography and the importance of information visualization. Some of the earliest known examples of computer-generated algorithmic art were created by artists such as George Nees, Frieder Nake, Manfred Mohr and Vera Molnar in the early 6o's. As a conclusion, we emphasize the idea that artists should use the computer as a tool adapted to their will, but understanding its potential to host systems that might allow the creation of artwork or graphics. In this regard, the computer must be considered a generative tool with a potential that must be understood in the context of the artist's work and intentions.
\end{abstract}

Keywords: computer art, coding, algorist, visualization.

\section{Introduction}

We hear often the assertion that we live in the midst of the post-digital era and that the contemporary art is based on new media, so, predictably, the computer has become a basic tool for the artist, but it is equally a tool for a surgeon, an architect or a biologist. Does the fact that the artist uses his computer make him a scientist, or can the surgeon become an artist? We started this chapter with this questioning on professional identity to emphasize that the technology does not produces art, but the artist is one who creates it, though there are many who hope that the new technological tools will replace eventually the talent, hard work and sensitivity that we are generically reuniting under the name "art".

With the new possibilities offered by new technologies, the graphic artists find themselves faced with the opportunity to create unprecedented images and forms. While some graphic artists were rejecting the digital technology, scorning those who chose to explore it, many others chose to embrace this innovative tool that allowed them to correct mistakes, change colors,

(C) Authors. Terms and conditions of Creative Commons Attribution 4.0 International (CC BY 4.0) apply. Correspondence: Ion Gherman, Constantin Stere Nr. 10B, Sc.B, Ap. 19, Timisoara, ROMANIA. E-mail: ion.gherman@e-uvt.ro. 
texture and images, to overlay them, to make them transparent, broader, tighter, to combine them in unprecedented ways.

In the mid-1980s, the emergence of desktop publishing and the introduction of software applications created a generation of designers specialized in manipulating computer images and creating 3D images, something that could not be achieved before. Computer-generated graphic design has allowed the designers to instantly see layout effects or typographic changes without using any ink during the process. The computers not only have facilitated the traditional design process but have provided a whole new perspective on sketching and forming ideas, allowing the designers to create virtually countless variations of a work - concept.

The digital art has become an essential component of the contemporary art and the new tools currently available to artists are revolutionizing the way these artists think and create, with the result that artistic productions that would not have been possible to be created traditionally, are now possible through computerized interfaces. Obviously, a significant change also occurred in the distribution of works of art, through the emergence of virtual museums and art galleries. In addition, the artwork crosses the borders more and more easily, quickly penetrates in all the corners of the world, and becomes instantly accessible to viewers from spaces which are thousands of miles away.

"That being so, the artwork is added to the structure of what we call 'networks' - these means of communicating information that are passing now through satellites, cables, satellite dishes, optic fibers, and are scattered throughout the planet as a netting with multiple ramifications. What can be the impact of these new productions, designed directly for 'canvas', immaterial and 'non-localized', because they are located 'everywhere'? Everything happens as if the image itself would lose what otherwise would have been its flesh, pigments, texture, density. The image becomes a ghost. The code triumphs" (de Mèredieu, 2005: 13).

The real beginning of the computer era happened in 1950, when the British mathematician and computer pioneer Alan Turing published a research describing what was later called the Turing test. The research explored the nature and potential of the development of human and artificial intelligence as well as the communications, while the first successful commercial electronic computer, UNIVAC, which was also the first computer for general use, was designed in the same year.

In the early years of using computers, access to this technology was a privilege that only researchers and scientists had. Their particular interests in certain areas of art or design and the results they have obtained from various experiments have attracted the attention of artists and arts students. Subsequently, the computers were integrated in architectural workshops, in design studios, and the universities integrated them into their study curriculum. The computer users, artists and scientists all the same, have also initiated the research of a new universe, a new environment of interaction for old and new art, establishing new forms, questioning the past, imitating traditional patterns and forms, or, on the contrary, breaking patterns and provoking the development of a new aesthetic code.

Currently, the technology is always a step ahead of us, and the use of the computer is part of our social practice, changing our way of interacting, giving another dimension to our own values, concepts and ideas, proving to be a challenging environment for the notion of art.

Probably many art historians believe that I agree with the fact that digital art remains difficult to fit into the historiography of traditional art. First of all, before any attempt to define it, it is appropriate to specify that the term digital art is often assimilated with the term computer art, or art generated by the computer.

To study the history of digital art, it is necessary to study the history of several disciplines: the history of the computer as a visual environment, the history of graphic design and 
the history of the computer in the visual arts. Often, these disciplines coincide over certain periods, making the study even more difficult to perform. For example, the history of computer art and the history of graphic design are virtually impossible to separate during the first decade, the borders between them remaining permeable and lax. In addition, the research requires specialized technical knowledge from the researcher.

Another issue that makes the research difficult is the complexity of the digital environment and the rapidity with which it has developed in a very short period of time. Unlike other traditional tools that have not changed their function and form for hundreds of years, the computer has evolved dramatically in a very short time.

\section{Coding and image}

The digital art can be defined as a visual manifestation that takes into account certain aesthetic criteria and is composed of information edited on the computer.

There are two distinct categories of approach to digital art, depending on how it was created: the one in which the artist interferes directly with the image and the one in which the artist creates an algorithm that will itself generate images according to the input data. This second case may be subject to controversy because the author must rather have knowledge in the field of informatics on the one hand and on the other hand he does not get in touch with the visual form of his project until the end.

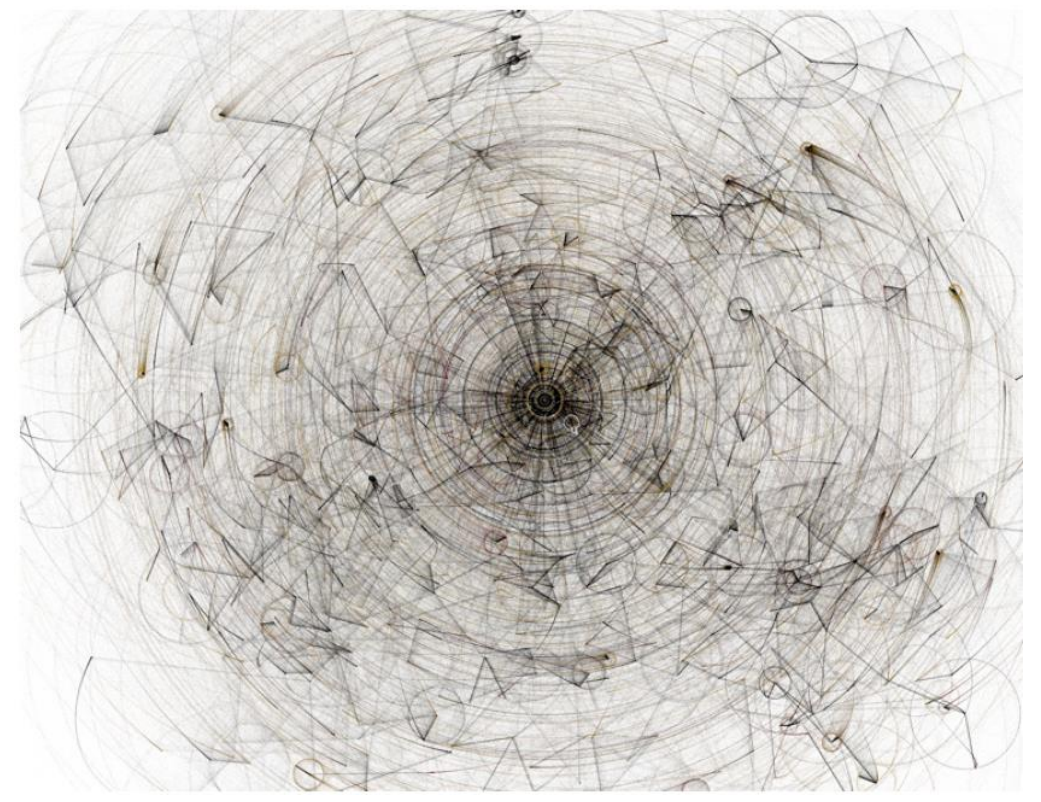

Image 1. Jared Tarbell, Orbitals (Variation B), 2004

From an aesthetic point of view, the digital technology interferes with the traditional art scene in two ways: approached as an independent environment and approached as a tool to produce works on traditional support.

It is therefore necessary to briefly present the pioneers of the digital art and the relationship between their works and the modern art. We will focus on the artistic activity of some reference names for the notion of computer art.

One of the first electronic artworks, Oscillon 40, belongs to Ben Laposky, a mathematician and American artist, being created in 1952. Thus Ben Laposky was the first to break the boundary between science and art when in the 1950s, photographed hundreds of waves, in 
various forms, which he obtained and altered with the help of an oscilloscope and called them Electronic abstractions or Oscillons. Laposky exhibited his works 188 times in more than 100 cities in 37 US states and 16 other countries in the world. Thus, he initiated the conceptual transition from scientific representation to artwork.

A few years later after Laposky, an Austrian writer and scientist, Herbert Franke used random number generators to create works of art similar to those of Laposky.

Since the 1960s, computer use has begun to grow, and its indirect influence is beginning to feel in all spheres of society.

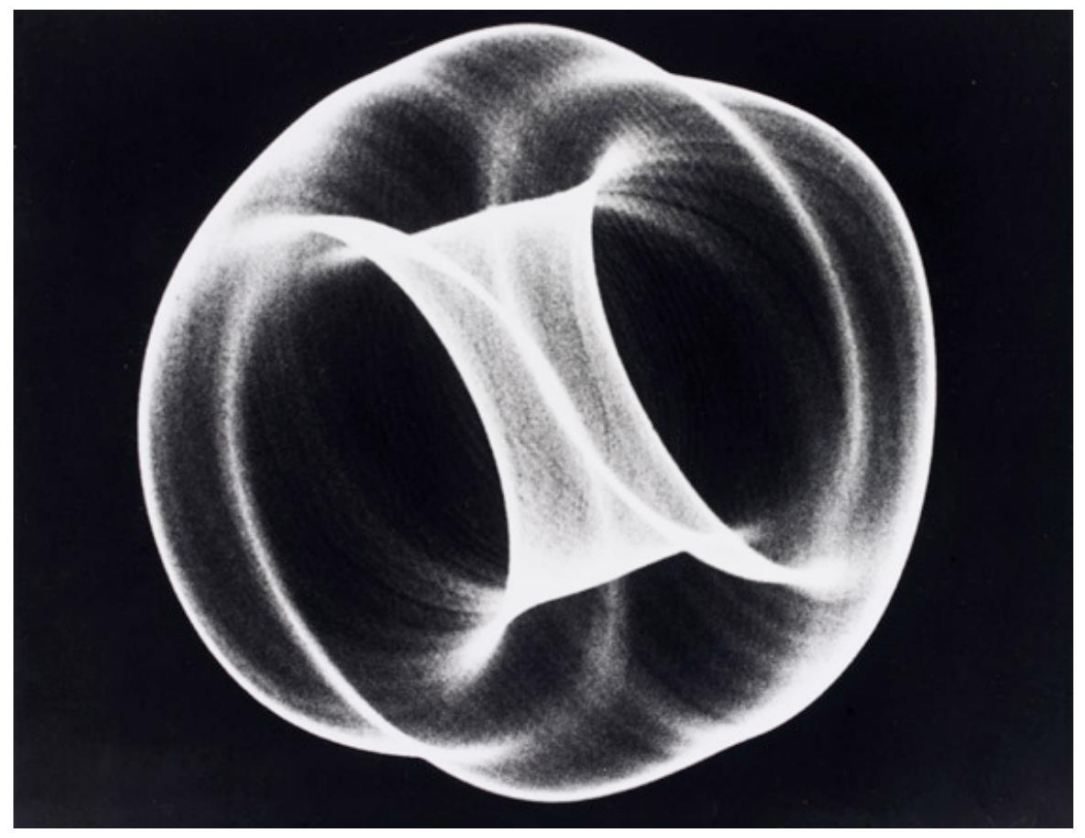

Image 2. Ben Laposky, Oscillon 4O, 1952

Unlike the United States, where the attitude towards computer was predominantly that related to a tool, in Europe, especially in Germany, the computer was an apparatus incorporating the rules and formulas of art (Taylor, 2014: 90). For the Europeans, it was not just a matter of experimenting in graphic design, of determining aesthetic rules, but also a desire to see if the computer can generate aesthetic properties. According to this idea, the mathematician and computer pioneer, Frieder Nake, who saw the potential of the computer to be a universal image generator capable of creating any possible image, simulated drawings by Paul Klee, which inspired him to see in visual art programming, an aesthetic tension both at the level of detail and at the overall level. His simulations consisted of linear structural elements, but also of groups of complicated local agglomerations.

In 1963, Charles Csuri built a computer to create a series of drawings inspired by classical painting (Durer, Klee, Ingres, Picasso, Goya and Mondrian). In the same year, Ivan Sutherland created a device that allowed people to interactively create images on a computer screen.

In 1965, Stuttgart was the first city to host the computer-generated art exhibition, including works by Frieder Nake, A. Michael Noll and George Nees. The works were exhibited at the Technological Institute (the current Technical University of Stuttgart) in February, and then at the Wendelin Niedelich Gallery in November. With artists such as Frieder Nake or Vera Molnar, the computer-generated art was already shaping its own aesthetics. 


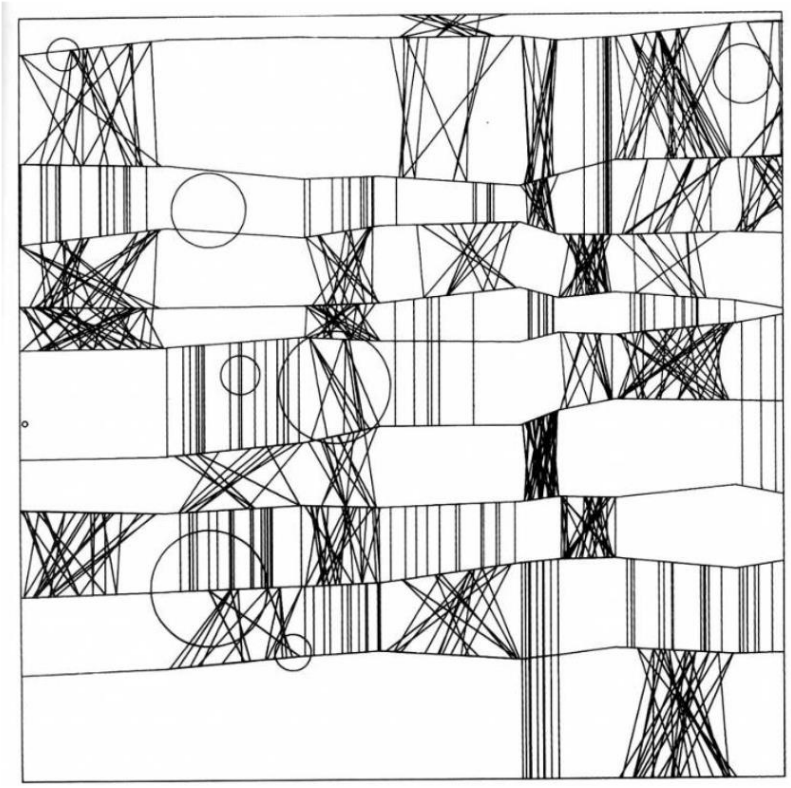

Image 3. Frieder Nake, 13/9/65 Nr. 2 (Paul Klee's homage), 1965, drawing plotter

In 1968, the Museum of Modern Art in the United States bought from Charles Csuri for its permanent exhibition the computer artwork entitled Hummingbird. In the same year was organized the first digital art exhibition, entitled Cybernetic Serendipity, hosted by the London Institute of Contemporary Art, having as its declared goal to investigate the role of cybernetics in contemporary art.

A year later, SIGGRAPH - Special Interest Group on Computer Graphics was created, organizing annual conferences on computer graphics, involving tens of thousands of professionals. Dozens of research papers are submitted each year. On a large scale, SIGGRAPH is considered to be the most prestigious forum for the publication of computer graphics research.

The digital art continued to progress, and in the '70s it was already quite common for artists to use the computer to create art. The audience also began to become more aware that art could also be created by using the computer, and the interest in the digital art continued to grow

In 1971, the Museum of Modern Art in Paris organized the first personal computer art exhibition of the artist Manfred Mohr. A few years later, in 1975, Europe's first inkjet printer was used by Herbert Franke to print a series of images of his. The patterns and colours were among the first mass productions of this kind. Even today they are available for purchase.

Among the many emerging artistic techniques, at the intersection of traditional art and new media, there is the algorithmic art or generative art, as it is called. The algorithmic art is a form of artistic creation based on the use of algorithms to generate visual images. Unlike traditional artworks, which are static and fixed, the algorithmic artworks are versatile and evolutionary, and can vary infinitely depending on the data input, they can be changed depending on certain variables. Throughout this research we have been able to see how in the Dada movement was promoted the art as a result entirely determined by hazard, while the Surrealist automatism freed the creative energies of the unconscious. However, the procedure for obtaining this random character in computer art differs from the procedures used by artists in the avant-garde movements. The artists had to define precisely the parameters in which the random character would be manifested, so it was an a priori thought process, programmed and controlled by the artist. For the artists, the random nature was rather a "metaphor of creativity, being in fact an effective means and a machine-made creation methodology" (Taylor, 2014: 92). 
Some of the first known computer-generated algorithms were created by the abovementioned artists George Nees, Frieder Nake, Manfred Mohr and Vera Molnar in the early 1960 . These artworks were made by a computer-controlled plotter, being thus computer-generated art, but we cannot yet speak of digital art.

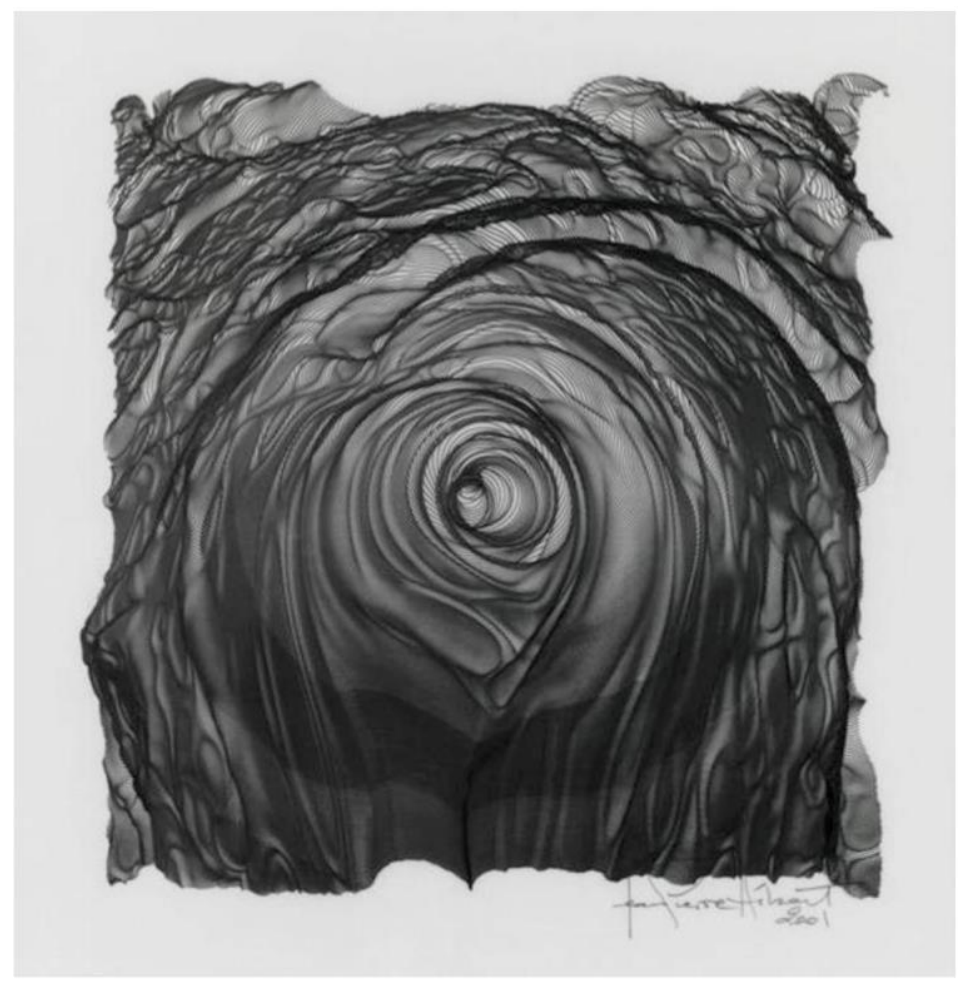

Image 4. Jean-Pierre Hébert, untitled, 2001

For an artwork to be considered algorithmic art, an algorithm designed by the artist must be included in its creative process. In this case, the algorithm represents the detailed design and execution recipe of the artwork. The artists who have created algorithmic art have been recognized under the generic name of algorists, name by which they began to identify themselves in 1995 at one of the SIGGRAPH conferences. The co-founders of this form of art are considered Roman Verostko and Jean-Pierre Hébert, the latter having the merit of being the inventor of the term and definition of this form of art, which, not surprisingly, was also given as an algorithm:

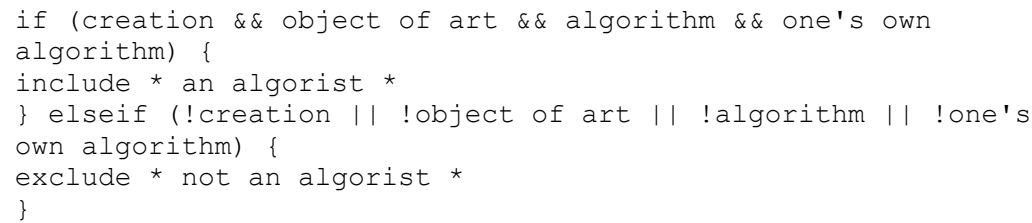

The process of writing an algorithm to generate a work of art is comparable to the writing of a musical score for a symphony. It is not enough to know programming and math, it requires vision, passion and a lot of aesthetic sense to create art, and programming is just a tool that supports the artist to accomplish the work. By using random numbers to determine when and where to place graphics, the artists have achieved new aesthetic configurations, new variations in shapes and images, and ultimately being able intervene to choose the parameters in which the most interesting object is produced.

The art of algorists uses a computer to execute the result in a physical environment chosen by the artist according to his preferences and interests, based on computer skills adapted 
to the characteristics of the materials chosen by the artist. They conceptualize their works both formally as a visual structure expressed in instructions and in physical form. From this point of view, the algorists create art made on a computer, but not based on it.

Former Benedictine monk and distinguished professor at Minneapolis College of Art and Design, Roman Verostko used the computer to generate floating diaphanous color veils, or multi-colored lines amalgamation, suggesting bizarre insects, or calligraphic writing in unknown languages, a fusion of human intelligence and mechanical precision. His series of works generically entitled Diamond Lake Apocalypse is an algorithmic reinterpretation of Illuminated Manuscripts. Created in the form of an open book, with the left and right pages, the works are deliberately designed as precious objects in the tradition of illuminated manuscripts.

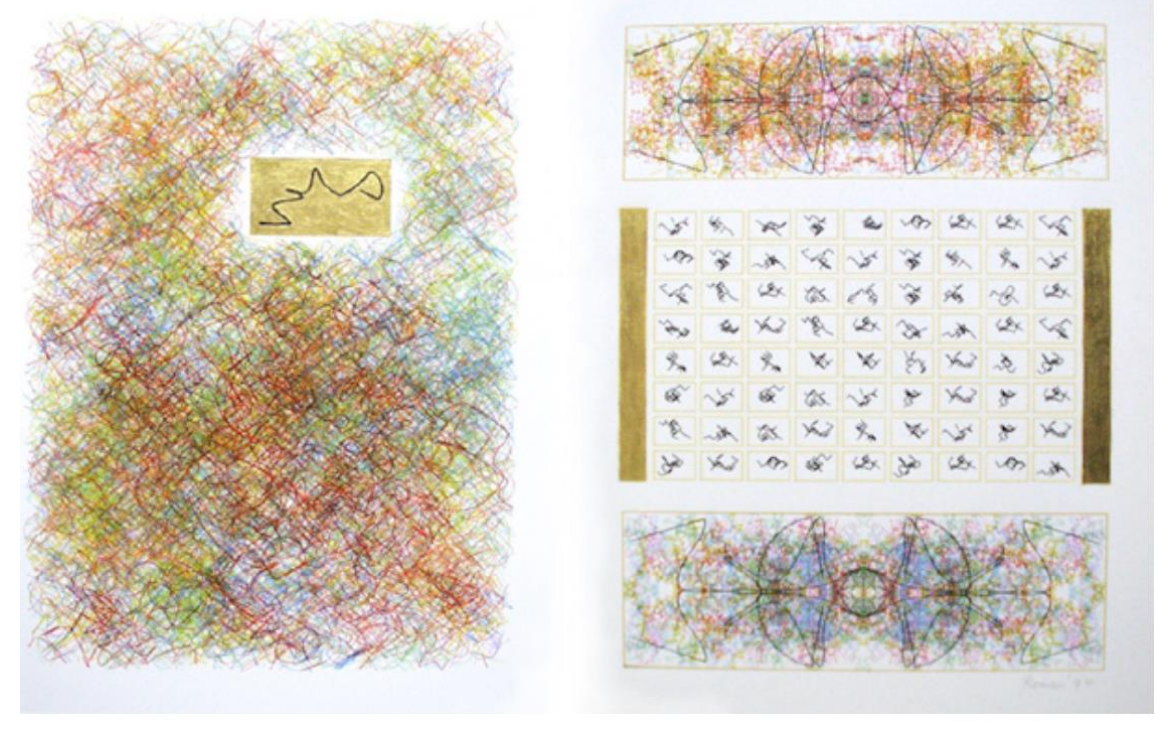

Image 5. Roman Verostko, Pathway, 1993

Just as medieval monks transformed the word written into "enlightenment," in the same manner, in this era, a graph plotter transforms an algorithm into a precious object. With the help of his plotters, the artist transforms his workshop into an electronic scriptorium, celebrating digital procedures in the form of illuminated scriptures. His workshop overlooks the Diamond Lake, which gave him the inspiration for the title of the series. The gold leaf, the element present on each work, manually applied by the artist, refers to the formal relationship with the enlightened manuscripts of the medieval period.

The works of Jean-Pierre Hébert, which are like fluid silk fabrics, illustrate eloquently that a computer can generate new visual possibilities and aesthetic explorations, and all this is a purely artistic process. Hébert develops a fascination for algorithmic formulas, however, he also appreciates paper and ink, preferring to exhibit his works in the form of drawings, probably because the paper provides a larger and more complex execution than the computer screen.

The dense textures of his works are built in an extremely elaborate manner, from lines at small distances from each other, resulting in various geometric shapes. The light and darkness also play an important role in some of his works. Hébert's involvement in the programming part, using the system for visual purposes, is an example of conceptual use of the computer in art. This use is an operational one, the computer being just a tool that serves rather to extend the artistic expression area. The flexibility of the computer allows him to be the central point or the main creative tool, but without leading to specific forms or restrictions. The totality of the image, system, tools and context depends on the instructions provided to the processor in the form of a code. 
"So my process is to compose, to choreograph a continuum of drawing and painting using algorithms that I code to serve my purpose. my work is freed from the physical constraints usual to drawing, so that I experience no limit in size or complexity, no muscle cramps, no fatigue, no visual strain; I can draw hair thin lines of extraordinary length, include them in networks, or model them in any shape and size I want; I can subject them to forces, fields, transformations; I can move beyond two dimensions to higher forms of space, and allow chance, time, sound, and all levels of additional information to be part of the work. I enjoy this freedom immensely, and I present some examples dating from the mid seventies to date" (jeanpierrehebert.com/10s.html).

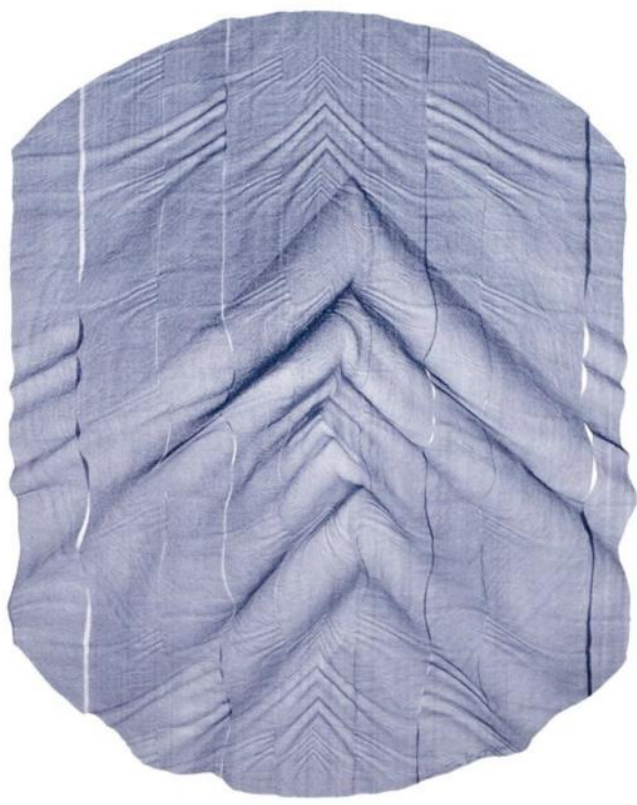

Image 6. Jean-Pierre Hebert, Mount Tai in blue mist, 2000

The artist transforms the mute material into a sense vehicle, processing its structure into shapes. The tools used to create art also become more than mechanical objects, and the resulting product is not an inherent property of their function, but a result of artistic thinking.

\section{Complexity of information visualization}

The people, from their birth, interact with the multitude of networks every day, from complex systems such as transport routes and communications networks, to less conscious interactions, frequent on social networks. Complex networks are everywhere. It is a structural and organizational principle found in almost every field we can think of, from human genes to power systems, from trophic chains to market share values. Currently, dozens of researchers around the world decode the networks around us using interfaces.

Visualisation, in the sense of a presentation, is not a new phenomenon. It has been used in maps, scientific drawings and date more than a thousand years ago. Examples are China's map (1137 BC) and the famous chart of the invasion of Russia by Napoleon in 1812, drawn by the French engineer Charles Joseph Minard. This classic chart, drawn in 1869, is considered to be one of the most successful graphic representations so far, precisely because of the simplicity and the amount of information it contains.

The beige colored line represents the French army, or the so-called Grand Army $(422,000)$ invading Russia in June 1812. The width of this line represents the size of the army at 
different moments in time. In September, the French army arrived in Moscow, but at that time the French army was practically destroyed, remaining with no more than 100,000 people. The route of Napoleon's retreat is indicated by the black line, which corresponds to a chart indicating the temperature at different moments in time.

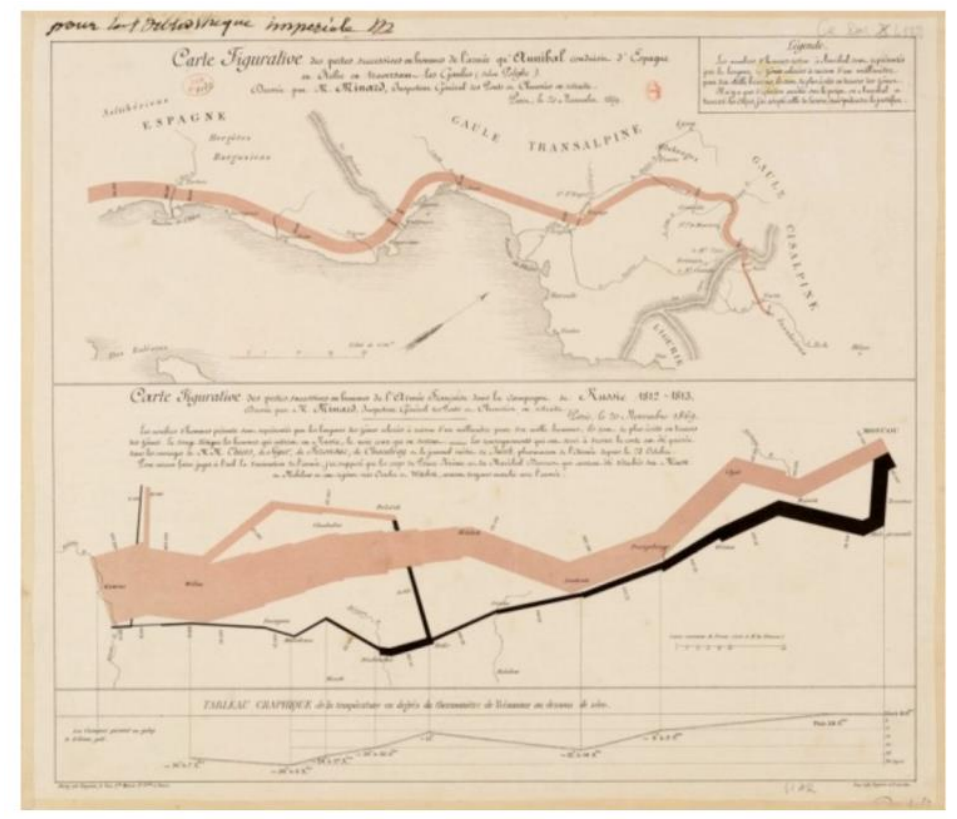

Image 7. Charles Joseph Minard, Napoleonic Invasion of Russia, 1869

Visualisation of information or scientific data is a branch of computer-aided graphics and a user interface that deals with the presentation of interactive or animated images designed for users to understand and evaluate data. For example, scientists interpret huge amounts of data, laboratory simulations, or sensor results. The data mining field provides many abstract visualisations related to these types of visualisations. Often, scientists and engineers collaborate with graphic artists and designers to create more powerful data visualization systems. This complex inter-connectivity of information has "contaminated" many artists in traditional areas such as graphics or painting.
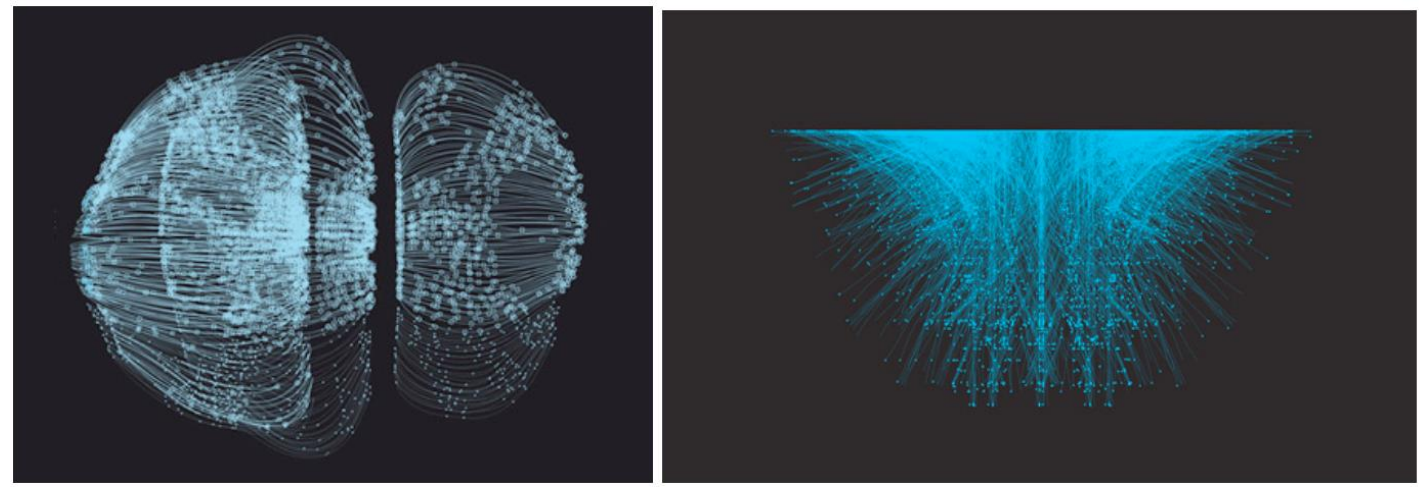

Image 8. Tatiana Plakhova, Networks, 2009 

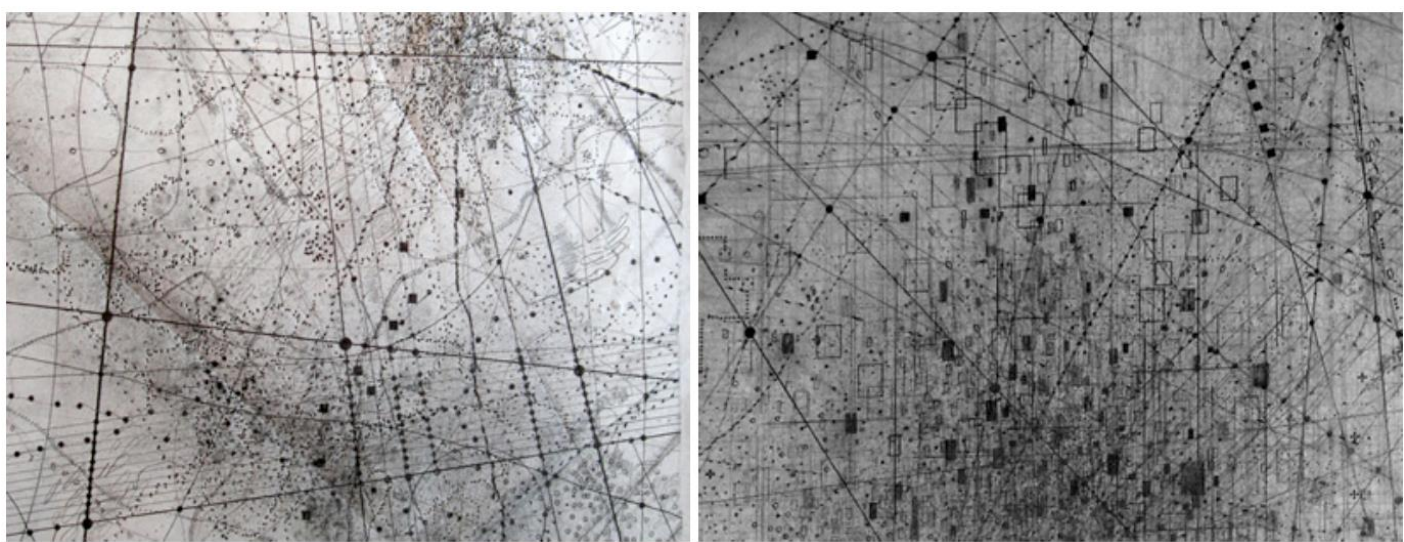

Image 9. Emma McNally, Drawings, 2009

Emma McNally's work shows us her preference for the complexity and theory of visualization systems. It is remarkable when this adoption takes the form of randomized algorithms in generated art, but it is even more astounding when it is expressed through manually drawn illustrations.

These charcoal drawings make us think of a mapping of imaginary routes. These intersections and nodal connections between lines, points, geometric shapes create an image of cyberspace and its networks.

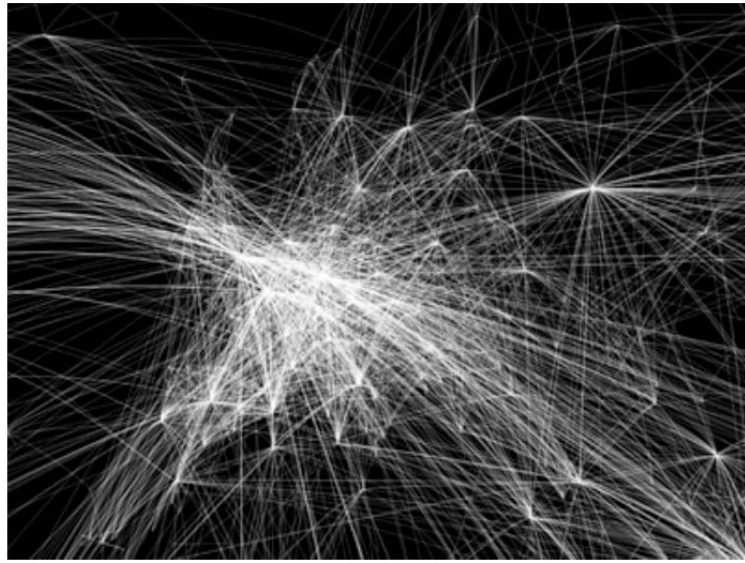

Image 10. Mario Freese, Air lines, 2009

Unlike the above mentioned authors above, Mario Freese creates these visualisations based on existing databases.

Air lines is a project aimed at mapping air routes around the world. Each scheduled flight on any given day is represented by a line from the take-off point to the destination airport, forming a network of thousands of lines.

The computer graphics has been used since its beginnings to study scientific issues. However, initially the lack of graphic power often limited its usefulness.

There have also been numerous books and research articles on visualization in recent years. Some of the most popular scientific visualisation examples are computer generated images that show real spacecraft in action, in vacuum, beyond the Earth, or on other planets. Dynamic forms of visualization, such as animation used in education, have the potential to enhance the learning capacity. 
Beyond the distinction between interactive visualisations and animations, the most useful classification is probably the one made between abstract scientific visualisations and modelbased visualisations. The abstract visualisations are completely conceptual constructions in 2D or 3D. These forms are completely arbitrary. The model-based visualisations are either data overlays on real or digitally reconstructed images based on reality, or are digital constructions of a real object, starting directly from the scientific data.

The scientific visualisation is usually made with specialized software, although there are some exceptions. Some of these specialized programs have been launched as open source software, many of them having their origins in universities.

The functional visualisations are more than statistical analyses and calculation algorithms. They need to be understood by the user and require a visual language system that includes color, shape, line and composition, to be able to communicate clearly and appropriately, being somewhat similar to the alphabet-based and character-based languages used globally by the people.

\section{Conclusion}

As a conclusion, we can point out the fact that the artists must make the computer a tool adapted to their will, but understanding its potential to host systems that allow the creation of works of art or graphics. The use of computers is part of a social practice that has already changed our concepts, explanations and values, and will continue to do so. In this sense, the computer must be considered as a generative tool, with a potential that must be understood in the context of the artist's work and intentions.

The computer managed to be included in the design courses of the art universities everywhere. The use of computers is part of a social practice that has already changed our concepts, explanations and values, and will continue to do so. However, computer-generated art will truly be integrated and accepted only when it loses its "unnatural" status, because of the way it was created. Undoubtedly, there is no way to return to the pre-digital world, even for the visual arts, still on the brink of this digital explosion. As artists and scientists, we are researching a new universe in which previous art and new art come in contact. Indeed, new art forms collide with established forms, question the past, and submit new values to their beneficiaries. The new sometimes starts out disguised as the traditional, mimicking accepted models and conventions. Other times it simply suggests a totally new aesthetic code.

Whatever its origin would be, computer-generated art carries the stamp of human creation, regardless of the degree of mediation made by and through the machine. It is our responsibility, and within our means, to master it, to make the best out of it.

\section{Acknowledgements}

This research did not receive any specific grant from funding agencies in the public commercial, or not-for-profit sectors.

The author declares no competing interests. 


\section{References}

de Mèredieu, F. (2005). Art and new technologies. Bucharest: Rao Encyclopedia.

Doss, E. (2202). Twentieth-century American art. Oxford: Oxford University Press.

Godfrey, T. (2008). Conceptual art. London: Phaidon Press Limited.

Morley, S. (2003). Writing on the wall. Thames \& Hudson/University of California Press.

Perjovschi, L. (2007). Contemporary art archive - Center for art analysis 1985-2007. Cluj-Napoca: Idea Design \& Print.

Taylor, G. D. (2004). When the machine made art: The troubled history of computer art. Bloomsbury Academic.

Web resources

http://digitalmediaartistry.wordpress.com/the-history-of-digital-art/. Accessed on 14 June 2018. http://spalterdigitalartcollection.blogspot.ro/2011 $05 \quad 01$ archive.html. Accessed on 28 May 2018. http://www.jeanpierrehebert.com. Accessed on 15 March 2018.

http://www.nadin.ws/archives/352. Accessed on 5 January 2017.

http://www.obxlabs.net/. Accessed on 28 September 2016.

http://www.studio-international.co.uk/books/artandtextog.asp. Accessed on 22 April 2018.

http://www.uoc.edu/artnodes/espai/eng/art/manovich1002/manovich1002.html. Accessed on 28 August 2015. http://www.vam.ac.uk/content/articles/a/computer-art-history/. Accessed on 17 March 2016.

http://www.vam.ac.uk/content/articles/a/computer-art-history/. Accessed on 19 March 2016. http://www.verostko.com/algorist.html. Accessed on 5 December 2017.

http://www.visualcomplexity.com/vc/index.cfm?domain=Art. Accessed on 24 May 2018.

http://www.visualnews.com. Accessed on 11 October 2013.

https://en.wikipedia.org/wiki/A._Michael_Noll. Accessed on 23 April 2018.

https://en.wikipedia.org/wiki/Algorithmic art. Accessed on 10 June 2018.

https://en.wikipedia.org/wiki/Charles Csuri. Accessed on 10 June 2018.

https://en.wikipedia.org/wiki/Digital art. Accessed on 14 April 2014.

https://www.academia.edu. Accessed on 14 September 2016. 